\title{
Do 'good values' lead to 'good' health-behaviours? Longitudinal associations between young people's values and later substance-use
}

\author{
Robert Young* and Patrick West
}

\begin{abstract}
Background: Past studies have linked certain values (traditional vs. individualistic) with adolescent substance-use. The aims of this study are to replicate cross-sectional research linking values and adolescent substance-use and to determine if such values predict future substance-use.

Methods: A longitudinal school-based survey of 2196 young people (age 15) followed up in early adulthood (age 18/ 19). Participants provided data about their beliefs and values at age 15 , and their substance-use (smoking, alcohol and drug-use) at ages 15 and 18/19. In addition data were collected about their social background (gender, risk-taking, deprivation, religion, etc).

Results: Cross-sectionally, young people with anti-authority values were more likely to use various substances, e.g. 17$67 \%$ more likely to regularly smoke (daily), drink (most days), or use drugs (weekly) for each SD above typical levels. Adjusting for social background, associations were not substantially attenuated. However in the prospective analysis, adjusting for both background and substance-use at age 15, only two (anti-authoritarian and work ethic) values were (marginally) associated with substance-use at age 18/19.

Conclusions: While we replicated results found in prior cross-sectional studies, evidence from this study does not support the argument that holding certain 'pro-social' or 'good' values substantively protects against later substanceuse and challenges the likely effectiveness of values-based interventions in relation to later substance-use.
\end{abstract}

\section{Background}

Character or values education is the policy of using the school curriculum to influence young people's values, typically promoting traditional and citizenship values. It is a topic which provokes controversy in its own right [13], even more so when linked to risky or health-compromising behaviours such as substance-use [4]. Proponents argue that because values are strong cognitive, emotionally significant guiding and organising principles in an individual's life, they substantially shape both their current and future health behaviours. However, surprisingly little research has ventured beyond simple cross-sectional analyses between young people's values and healthbehaviours. Accordingly, we examine the longitudinal association between values and substance-use (tobacco,

\footnotetext{
* Correspondence: robert@sphsu.mrc.ac.uk

${ }^{1}$ MRC Social and Public Health Sciences Unit, University of Glasgow, 4 Lilybank Gardens, Glasgow G12 8RZ, UK

Full list of author information is available at the end of the article
}

alcohol and illegal drug-use), a topic of considerable current public health concern.

Before reviewing the limited evidence linking values and substance-use, we briefly outline the controversies surrounding values or character education, define what 'personal or human values' are and how such values are measured.

\section{Controversies in values education}

Proponents of values education make strong claims for its effectiveness, as for example in Lickona's 'Combating Violence With Values: The Character Education Solution' [4]. These claims are contested equally strongly by opponents such as Law [1]. Proponents (typically with religious affiliations) argue that promoting basic values such as equality, citizenship and obedience is not only intrinsically worthwhile but also bestows positive health [4]. Representatives of the liberal/secular position argue for the promotion of values such as freedom of expression or 
action, while acknowledging they often conflict with traditional values, e.g. blasphemy [1] (the challenge by free speech advocates towards the new 2010 Irish blasphemy law is a recent European example: http://news.bbc.co.uk/ 1/hi/world/europe/8437460.stm).

Much of the debate originates in America, with expresident George W. Bush among the many advocates of character education [1]. During his period of office, the US Department of Education allocated approximately $\$ 25,000,000$ each year from 2002-6 to developing school character programs http://www.ed.gov/programs/charactered/funding.html. However, the topic is relevant beyond the American context since virtually all western educational systems incorporate some form of values education. For example, in the UK much of what could be termed values education (particularly citizenship) is covered in the Personal and Social Education curriculum [5].

The debate is largely conducted in the absence of any reliable evidence, with a recent Australian government review summarising the evidence base thus: "Values education can be described, according to the literature review, as a subject about which much has been written but little is known." (page 33) [6]. Against this background, arguments about what constitutes the most appropriate values to promote, or which values lead to good health, remain unsubstantiated.

\section{Values}

If there is a lack of empirical evidence in relation to values education, the opposite is true for the psychological study of values. There is extensive cross-cultural agreement regarding the measurement and structure of values, which are broadly defined as "desirable goals, varying in importance, that serve as guiding principles in people's lives." [7]. The additional file 1 outlines one leading framework by Schwartz [8,9]. Briefly, Schwartz defines ten generic values: benevolence, universalism, self-direction, stimulation, hedonism, achievement, power, security, conformity, and tradition. For example, conformity is defined as "restraint of actions, inclinations, and impulses likely to upset or harm others and violate social expectations or norms" [10] and is measured by opinions such as the importance of honoring elders and obedience. Further, the ten values can be collapsed into two perpendicular poles, each quadrant representing typical groupings (openness-to-change vs. conservation and self-transcendence vs. self-enhancement; figure 1 and additional file 1). In our study, these two poles and four groups of values can be summarised as traditional (Schwartz's conservation) vs. self-direction (Schwartz's openness-to-change) and humanitarian (Schwartz's universalism) vs. selfenhancement values.

Based on rigorous empirical research, the framework of values described by Schwartz maps reasonably well onto

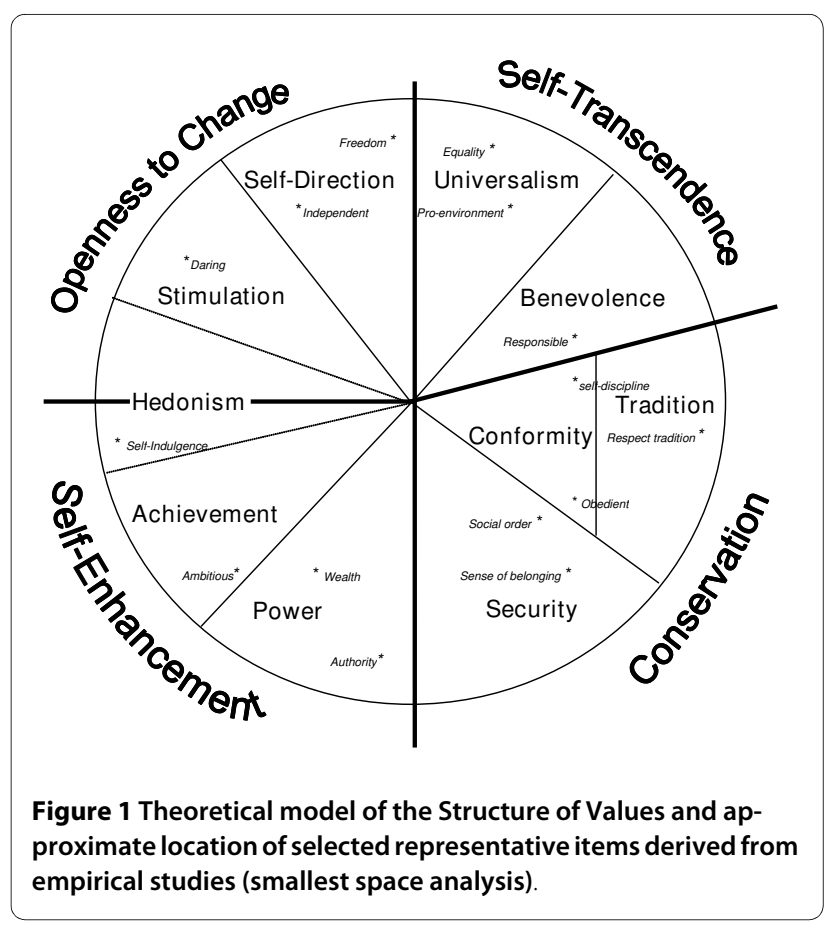

the framework of values used by policymakers. For example, the ten school values derived from the Australian Government's 'Values Educations Study' include: Social Justice (pursuit and protection of the common good) and Excellence (seeking to accomplish something noteworthy and admirable). These are compatible with Schwartz's universalism (humanitarian) and achievement (selfenhancement) values (see additional file 1). The congruence between policymakers, pedagogic and psychological perspectives provides further evidence that values are universally recognised $[8,9]$ and that all three perspectives can assess similar values irrespective of the exact measurement instrument used [11].

\section{Values and behaviour}

Among the few existing studies, there is evidence that specific values relate to a number of everyday (not exclusively health-related) behaviours in a plausible manner. In a convenience sample of undergraduates, Bard \& Schwartz [10] found strong concordance between several (self-reported) behaviours such as 'observing traditions and holidays' and the appropriate value (tradition), including some that could be considered health-risks. Achievement values were associated with stress-related behaviours (taking on too many commitments) and hedonism with over-eating. Both hedonism/stimulation and traditional values were strongly linked to aggregate measures of appropriate hedonistic or traditional behaviours $(r$ >.62). Further, when self-reported behaviours were substituted with partner or peer ratings of participants' behaviours the association remained strong, pro- 
viding further validation. While Bard and Schwartz [10] provide evidence of a link between values and very general behaviours, our focus is on specific health-compromising behaviours.

\section{General substance-use/risk}

Even fewer studies have examined the link between young people's values and health-related behaviours, but of these, most concentrate on substance-use. We briefly review this literature, finding strong cross-sectional associations, but also considerable methodological limitations.

One difficulty is that much research has conflated different types of risk-behaviours, sometimes creating a composite risk-score from a disparate selection of problem behaviours encompassing sexual behaviour, violence, substance-use, etc [12]. In a recent cross-sectional study of 10-12 year old school children from the Bahamas, certain values (conservative/traditional) were associated with fewer, and others (self-enhancement/achievement) with greater problem behaviours, although the latter result applied only to boys [12].

Using a composite indicator of substance-use in schoolchildren (ages 10-11) Cole et al. [13] found only traditional (conformity, tradition, security) and humanitarian (benevolence, universalism/equality) values were associated with lower substance-use. However, a family study of American adolescents (aged 18), found that while traditional values were again protective, humanitarian (humanitarianism and equality) values were associated with higher (general) substance-use [14]. This last result may be attributable to the over-sampling of 'unconventional families'. Garnier and Stein $[15,16]$, in a study somewhat similar to our own but focusing on 205 conventional and unconventional families, found no relationship between a composite substance-use indicator and two composite indicators of teen (aged 18) values labelled traditional/achievement and humanitarian/egalitarian values respectively. However, it is difficult to draw conclusions in relation to specific substances-use from this and similar studies because of the aggregate outcomes used, and the unrepresentative nature of the families involved.

\section{Specific substance-use}

In a study of high school student's (ages 15-16) problem behaviours, achievement (being well-respected) values were associated with lower, and hedonistic (fun and enjoyment) values with higher use of three substances (smoking, alcohol, and marijuana) [17]. Additionally, higher rates of smoking and alcohol (but not marijuana) were linked to achievement values (self-respect/accomplishment).

One diary study investigating alcohol-use among college students found alcohol consumption moderately correlated with both hedonistic $(r=0.21-.29)$ and selfenhancement values $(r=0.36)$ values, but negatively cor- related with humanistic (universalism and benevolence, $\mathrm{r}$ $=-0.22-.25$ ) values [18]. Additionally, traditional (tradition, conformity) values were associated with reduced problem-drinking.

Few studies have focused exclusively on smoking and values. In a random sample of UK adults, heavy-smokers held stronger achievement and hedonistic (social recognition, exciting life) values while light-smokers held more traditional and humanistic (family/national security, salvation, inner harmony) values [19]. A replication with Canadian students found that while non-smokers possessed greater humanistic (wisdom and beauty) values, smokers prioritised self-direction and self-enhancement (freedom, broadmindedness, independence, social recognition) values [20].

More recently, a study by Chen [21] examined 'terminal' and 'instrumental' values and smoking in young Chinese medical students, reporting that both were associated with smoking. Terminal values are those focused on endgoals, thus seeking either a comfortable or an exciting life are both terminal values. In contrast, instrumental values focus on conduct, e.g. valuing independence or obedience. The study's strength was that it controlled for relevant confounds (age, gender, race, sensation seeking), but because it focused on the function (terminal vs. instrumental) rather than specific types (e.g. traditional vs. anti-authority) of values, comparison with the larger literature is precluded.

\section{Summary}

In summary, although the evidence-base is limited (often restricted to student populations), a consistent finding is that traditional values are protective, while self-direction (independence) values are risk factors for substance-use. Self-enhancement (ambition) values can be protective or not dependent upon the context, age group or substance, e.g. they are potentially a risk factor in environments with a work-hard, play-hard ethos such as college. Humanitarian values are also inconsistently associated with substance-use, possibly because of the association between cannabis-use and peace-activist/humanitarian movements.

However, the evidence-base remains inadequate for at least two reasons. Firstly, only a few [12,21] studies have adjusted for relevant confounds such as gender, parental substance-use, family structure, religion, social background or school. In addition, although sensation or riskseeking is strongly associated with substance-use, few studies have examined its impact on the association between values and substance-use [12,21]. Secondly, and most importantly, no study has adjusted for prior substance-use; in the absence of longitudinal studies, it is impossible to evaluate how well values predict future substance-use. 


\section{Aims}

Using a large representative longitudinal sample of young people, surveyed at ages fifteen and again at 18/19, we have three aims; first, to replicate previous cross-sectional studies finding associations between values and smoking, alcohol-use and drug-use; second, to determine if these associations remain after adjustment for relevant confounds; third, to establish if values predict future substance-use at age 18/19, after adjusting for both confounds and past health-behaviour.

\section{Methods}

The material for the study is drawn from a Scottish longitudinal community health and lifestyle survey of young people, administered first in-school via questionnaire (ages 11, 13, and 15) and then in the post-education period by nurse interview at age $18 / 19$. The focus here is on data collected between 1999 (aged 15) and 2003 (age 18/19) within the framework of the 'West of Scotland 11 to 16 Study/16+' [22]. The study received approval from Glasgow University's Ethics Committee, participating Education Authorities and schools, and informed consent was obtained from the parents of all participants via 'optout' consent forms at ages 11, 13 and 15, verbal consent from participants at each wave and written consent at age $18 / 19$.

Due to the school-based nature of the sample the sampling scheme involved several elements to ensure a representative sample at both the primary and secondary school stages and sufficient school units to investigate or control for school-level clustering [23]. Briefly, the survey used a reverse sampling procedure which randomly selected 43 secondary schools stratified by religious denomination and deprivation, with a separate stratum for independent vs. local authority run schools. These 43 secondary schools were used to select a random sample of 135 primary schools, comprising 'feeder schools', together with those making a high number of placing requests. From these primary schools, classes were randomly selected with all pupils in the classes eligible to participate. Of the 2793 pupils who attended the 43 targeted secondary schools, 2586 (93\%) participated in the baseline (age 11) survey. At age 13, the number of participants reduced to 2371 (85\%), and by 15 to 2196 (79\%), as expected losses in the post-school period substantially reducing the sample size at age $18 / 19$ to 1256 (45\%). Full details of the sampling strategy are available elsewhere [23].

At age 11 the sample was representative (in terms of sex and social class composition) of 11 year olds in the study area [24]. Differential attrition made later waves less representative, with attrition greater among lower social class groups, school truants, pupils of lower ability and with greater emotional and behavioural problems. To compensate for these biases, a weighting scheme was derived [24]. Use of these weights did not substantively alter any of the results presented here. The data used in this paper refer to 2196 pupils in their final year of compulsory education in 43 mainstream secondary schools in the Glasgow area, 1256 of whom provided information when aged 18/19. Parents provided information on pupils' religious background and family socioeconomic status via a supplementary questionnaire in the first wave (age 11) of the study.

\section{Measures}

In 1999 (aged 15) pupils were asked to rate on a 5-point Likert scale (strongly agree to strongly disagree) how much they endorsed 32 questions relating to values and social attitudes, derived from a number of well-established studies of young people's values [25-28] (see additional file 2). Principal components analysis (varimax) reduced the 32 items to eight factors accounting for $45 \%$ of the variance (see additional file 1). The eight factors are broadly comparable with the generic values found by other researchers and each can be located within Schwartz's circumplex model (see additional file 1), and are labeled as follows; Traditional sex-roles (Schwartz's Tradition), e.g. 'Some equality in marriage is a good thing but by and large the husband ought to have the main say'; Work Ethic (Schwartz's Conformity: self-discipline), e.g. 'Even if I didn't like the work, I would still want to do it as well as I could'; Equity (Schwartz's Universalism: equality), e.g. 'The government should tax the rich more in order to help the poor'; Citizenship and sense of belonging (Schwartz's Security: sense of belonging), e.g. 'It is a privilege to be Scottish'; Anti-authority (Schwartz's Anti-tradition: no respect for tradition/obedience), e.g. 'Young people today don't have enough respect for traditional values' (reverse scored); Anti-traditional - apolitical or environmentalist - politics (Schwartz's Universalism/AntiPower: protect environment), e.g. "There should be restrictions on car drivers in the city to cut down on pollution'; Materialism (Schwartz's Power/Achievement: wealth, successful), e.g. 'There's nothing wrong with having a big house or an expensive car'; Individualism (Schwartz's Power/Anti-Universalism: social power, social justice), e.g. 'The idea that society owes you a living is out of date'. The vast majority of these items have been validated in past studies, but they do not originate from established values scales. However, given the universal nature of values and the high face validity of many items it is highly likely our items are strongly correlated with equivalent items drawn from an established values scale e.g. "Parents can tell you what to do" (our item) Vs "Honoring parents" (equivalent item Schwartz values scale; see figure 1 and additional file 1 ). 
Several background factors related to either values or substance-use at age 15 were recorded. An area deprivation score, range 1 (least) to 7 (most deprived), was derived from pupils' postal codes using the 'Carstairs' [29] index, a standard measure based upon census data. Social class of the head of household was derived from parental questionnaires completed at wave one (age 11), coded using the standard UK classification system [30] and categorized as non-manual, manual, or missing. Religious affiliation was obtained from parents and categorized, Church of Scotland (Protestant), Catholic, Muslim, other (Jewish, Methodist, Baptist, etc) and 'none, atheist/agnostic'. At age 15, pupils family structure was coded as 2-parent, 1-parent, reconstituted (one 'birth' parent and new partner) or other (relative, foster parent, or other carer). Principal component (varimax) analysis of the (age 15) 6item Brief Parental Bonding Instrument [31], produced two scales representing (low) parental care, e.g. 'My parents help me as much as I need' (reversed) and (high) control, e.g. 'My parents treat me like a baby'. At age 15, pupils reported parental smoking status which was used as a proxy for parental substance-use. At age 15, a generic 4-point Likert (very true to very untrue) scale asked pupils if they identified as a 'risk-taker' and is arguably a good proxy for stimulation and hedonistic (desiring an exciting/varied life) values. Due to low cell frequencies very untrue and untrue categories were collapsed for analysis.

With respect to measures of substance-use at ages 15 and $18 / 19$, smoking was defined as regular smoking, derived from a 5-point frequency scale (never smoked, tried, used to, occasionally or regularly smoke) and is similar to that used by the UK Office for National Statistics [32]. Alcohol-use was assessed on a 7-point frequency scale ('every day' to 'I never had an alcoholic drink') and dichotomized into frequent (drink most days) vs. less frequent use. Pupils reported using a variety of illegal (primarily marijuana) drugs, dichotomized into weekly drug-use vs. less frequent use. In order to assess if our results also applied to moderate levels of substanceuse, an additional set of indicators with a lower threshold were chosen for smoking (regular or occasional), alcohol (drank weekly) and drug-use (ever used). Since the results of both sets of analyses were very similar, we elected to present the more severe outcomes because of their greater relevance to public health. Those relating to more moderate outcomes are available upon request.

\section{Statistical analysis}

The analysis used logistic regression to determine the association between values at age 15 and both concurrent and later (age 18/19) substance-use. Analysis was conducted first unadjusted and then adjusted for background factors and included past substance-use for age 18/19 outcomes. We constructed weights to compensate for differential attrition (21), but use of these weights did not alter results, nor did adjusting for school clustering (either via multilevel modeling or adjusting estimates for clustering). The influence of missing data was further explored by comparing results for models using three different methods for dealing with missing data; complete data only; including an additional missing data category for variables with more than modest amounts (50+ cases) of missing data and multiple imputation methods. Multiple imputation was implemented using the STATA 'ice' procedure and included all variables from the relevant model. Categorical variables were imputed using logit or multiple logit, continuous variables using regression and deprivation using ordinal logit commands. Ten imputed datasets were used to calculate the final combined estimates. Although the results for each method were not substantively different, we report results based on multiple imputation. Results from all other alternative models are available upon request.

\section{Results}

\section{Univariate results}

Table 1 reports descriptive statistics of each of the variables, including the number of cases with missing data for each variable. The substance-use outcomes display the typical pattern expected between ages 15-18/19, showing increased use of all three substances. However, the increase is most noticeable for alcohol-use.

\section{Cross-sectional results}

Table 2 shows the contemporaneous associations between values and substance-use among 15-year olds. All but two values (citizenship, a key value for policymakers and materialism) significantly predict at least one type of substance-use at age 15, although the effect size varies from small to moderate. Remarkably, there is only modest attenuation when nine background variables are included in our models.

With the single exception of alcohol-use, both antiauthority and anti-traditional politics predicted increased substance-use of any type, with anti-authority typically the strongest predictor. Traditional sex-roles also predicted increased substance-use irrespective of type, although only in the adjusted model in relation to smoking. Work ethic was associated with increased regular smoking, individualism with lower smoking and drug-use and equity with a significant, but small, increase in smoking.

\section{Longitudinal results}

Table 3 presents the longitudinal results, testing how well values at age 15 predict substance-use at age 18/19, unadjusted and adjusted for background factors. Although 
Table 1: Frequencies of categorical predictors at age 15 and outcomes at age 15 and 18/19 variables.

\begin{tabular}{|c|c|c|}
\hline Categorical variables & $\mathbf{N}$ & Frequency (\%) \\
\hline \multicolumn{3}{|l|}{ Sex $($ miss $=0)$} \\
\hline Female & 1080 & 49.18 \\
\hline Male & 1116 & 50.82 \\
\hline \multicolumn{3}{|l|}{ Parental Smoking (miss $=6$ ) } \\
\hline No & 547 & 24.98 \\
\hline No parent figure & 32 & 1.46 \\
\hline Yes & 1,611 & 73.56 \\
\hline \multicolumn{3}{|l|}{ Social Class $($ miss $=161)$} \\
\hline Manual & 1,069 & 52.53 \\
\hline Non-manual & 966 & 47.47 \\
\hline \multicolumn{3}{|l|}{ Family structure (miss $=0$ ) } \\
\hline 2-parent & 1571 & 71.54 \\
\hline 1-parent, & 351 & 15.98 \\
\hline reconstituted & 224 & 10.20 \\
\hline other & 50 & 2.28 \\
\hline \multicolumn{3}{|l|}{ Religion (miss $=277$ ) } \\
\hline Protestant & 813 & 42.37 \\
\hline Roman Catholic & 653 & 34.03 \\
\hline Muslim/Islam & 48 & 2.50 \\
\hline Other (Baptist, Jewish, etc) & 112 & 5.84 \\
\hline None/Atheist/Agnostic & 293 & 15.27 \\
\hline \multicolumn{3}{|l|}{ Risk taking (miss $=11$ ) } \\
\hline Very true & 205 & 9.38 \\
\hline True & 1,188 & 54.37 \\
\hline Untrue or very untrue & 792 & 36.25 \\
\hline
\end{tabular}

Substance-use outcomes (moderate)

Smoking*, age 15 (miss $=2$ )

\section{Substance-use outcomes (severe)}


Table 1: Frequencies of categorical predictors at age 15 and outcomes at age 15 and 18/19 variables. (Continued)

\begin{tabular}{ll}
\hline Illegal drugs, weekly use, age 15 (miss = 5) & 265 \\
Illegal drugs, weekly use, age 18/19 & 154 \\
(miss = 980) & \\
\hline${ }^{*}$ Occasional or regular smoking; ${ }^{* *}$ regular smoking & 12.66 \\
miss = missing values & \\
Note: 94 cases had missing values on the eight values factors, 145 on the area deprivation score and 1 case on the low parental care and \\
control scales.
\end{tabular}

Table 2: Cross-sectional associations between values and regular substance-use at age 15 , unadjusted and mutually adjusted odds-ratios.

\begin{tabular}{|c|c|c|c|c|c|c|}
\hline \multirow[b]{2}{*}{ Predictors } & \multicolumn{2}{|c|}{ Regular smoker } & \multicolumn{2}{|c|}{ Frequent (most days) drinker } & \multicolumn{2}{|c|}{ Weekly drug-use } \\
\hline & Unadjusted & Adjusted & Unadjusted & Adjusted & Unadjusted & Adjusted \\
\hline \multicolumn{7}{|l|}{$\underline{\text { Traditional }}$} \\
\hline (Trad) Sex-Roles & $1.09(0.96-1.23)$ & $1.22(1.05-1.41)$ & $1.60(1.24-2.07)$ & $1.40(1.09-1.81)$ & $1.67(1.45-1.92)$ & $1.53(1.30-1.81)$ \\
\hline (Pro) Work Ethic & $1.17(1.03-1.32)$ & $1.18(1.04-1.33)$ & $1.13(0.84-1.51)$ & $1.10(0.85-1.44)$ & $1.11(0.96-1.28)$ & $1.06(0.91-1.24)$ \\
\hline (Pro) Citizenship & $1.04(0.93-1.16)$ & $1.06(0.94-1.20)$ & $1.09(0.83-1.44)$ & $1.14(0.88-1.48)$ & $1.03(0.89-1.19)$ & $1.01(0.87-1.18)$ \\
\hline \multicolumn{7}{|l|}{ Humanitarian } \\
\hline (Pro) Equity & $1.27(1.15-1.42)$ & $1.25(1.12-1.39)$ & $0.97(0.77-1.21)$ & $0.99(0.78-1.24)$ & $1.13(0.97-1.30)$ & $1.09(0.93-1.27)$ \\
\hline \multicolumn{7}{|l|}{ Self-direction } \\
\hline (Anti) Authority & $1.53(1.35-1.74)$ & $1.33(1.17-1.51)$ & $1.67(1.31-2.13)$ & $1.33(0.98-1.79)$ & $1.64(1.40-1.91)$ & $1.45(1.21-1.75)$ \\
\hline (Anti-trad) Politics & $1.49(1.35-1.64)$ & $1.39(1.23-1.57)$ & $1.41(1.08-1.83)$ & $1.38(1.02-1.77)$ & $1.48(1.31-1.67)$ & $1.32(1.17-1.49)$ \\
\hline \multicolumn{7}{|l|}{$\underline{\text { Self-enhancement }}$} \\
\hline (Pro) Materialism & $0.99(0.88-1.11)$ & $0.96(0.85-1.09)$ & $1.08(0.78-1.48)$ & $0.99(0.72-1.36)$ & $1.11(0.94-1.31)$ & $1.04(0.87-1.23)$ \\
\hline (Pro) Individualism & $0.83(0.72-0.94)$ & $0.84(0.73-0.96)$ & $0.88(0.66-1.17)$ & $0.86(0.64-1.14)$ & $0.77(0.65-0.91)$ & $0.78(0.66-0.92)$ \\
\hline \multicolumn{7}{|l|}{ Parental Smoking } \\
\hline No & 1.00 & 1.00 & 1.00 & 1.00 & 1.00 & 1.00 \\
\hline $\begin{array}{l}\text { No parent } \\
\text { figure }\end{array}$ & $2.20(0.95-5.10)$ & $1.27(0.35-4.64)$ & $5.78(1.86-17.93)$ & $2.24(0.19-27.21)$ & $3.36(1.63-6.94)$ & $2.03(0.55-7.56)$ \\
\hline Yes & $1.73(1.40-2.15)$ & $1.36(1.04-1.76)$ & $0.82(0.44-1.53)$ & $0.91(0.45-1.87)$ & $1.64(1.25-2.15)$ & $1.40(1.00-1.96)$ \\
\hline \multicolumn{7}{|l|}{ Risk taking } \\
\hline Very true & $5.25(3.75-7.36)$ & $4.25(2.89-6.26)$ & $\begin{array}{c}10.01(4.95- \\
20.23)\end{array}$ & $4.26(1.84-9.85)$ & $\begin{array}{c}10.98(6.66- \\
18.11)\end{array}$ & $5.94(3.52-10.03)$ \\
\hline True & $2.74(2.16-3.48)$ & $2.33(1.79-3.04)$ & $2.95(1.27-6.86)$ & $1.87(0.74-4.69)$ & $4.12(2.83-6.00)$ & $2.81(1.90-4.16)$ \\
\hline $\begin{array}{l}\text { Untrue/v } \\
\text { untrue }\end{array}$ & 1.00 & 1.00 & 1.00 & 1.00 & 1.00 & 1.00 \\
\hline \multicolumn{7}{|l|}{ Sex } \\
\hline Female & 1.00 & 1.00 & 1.00 & 1.00 & 1.00 & 1.00 \\
\hline Male & $0.73(0.58-0.93)$ & $0.50(0.37-0.66)$ & $2.84(1.56-5.14)$ & $1.82(0.97-3.40)$ & $1.90(1.45-2.49)$ & $1.10(0.80-1.52)$ \\
\hline Area deprivation & $1.02(0.96-1.10)$ & $0.93(0.86-1.00)$ & $0.88(0.78-0.99)$ & $0.85(0.75-0.96)$ & $1.09(1.01-1.19)$ & $1.02(0.93-1.13)$ \\
\hline
\end{tabular}


Table 2: Cross-sectional associations between values and regular substance-use at age 15, unadjusted and mutually adjusted odds-ratios. (Continued)

\begin{tabular}{|c|c|c|c|c|c|c|}
\hline \multicolumn{7}{|l|}{ Social Class } \\
\hline Manual & 1.00 & 1.00 & 1.00 & 1.00 & 1.00 & 1.00 \\
\hline Non-manual & $0.72(0.56-0.93)$ & $0.86(0.67-1.09)$ & $1.02(0.67-1.54)$ & $1.05(0.66-1.67)$ & $0.65(0.48-0.88)$ & $0.84(0.57-1.23)$ \\
\hline \multicolumn{7}{|l|}{ Family structure } \\
\hline 2-parent & 1.00 & 1.00 & 1.00 & 1.00 & 1.00 & 1.00 \\
\hline 1-parent & $2.19(1.65-2.91)$ & $1.78(1.29-2.45)$ & $0.91(0.49-1.69)$ & $0.79(0.37-1.67)$ & $1.88(1.42-2.49)$ & $1.41(1.03-1.93)$ \\
\hline reconstituted & $2.07(1.47-2.93)$ & $1.71(1.18-2.50)$ & $1.49(0.72-3.05)$ & $1.42(0.64-3.16)$ & $1.86(1.24-2.78)$ & $1.60(1.07-2.40)$ \\
\hline other & $1.95(1.04-3.66)$ & $1.19(0.46-3.05)$ & $5.65(2.17-14.71)$ & $3.34(0.44-25.27)$ & $2.88(1.42-5.82)$ & $1.46(0.49-4.36)$ \\
\hline Low parental care & $1.24(1.15-1.33)$ & $1.11(1.04-1.19)$ & $1.34(1.17-1.53)$ & $1.19(1.00-1.40)$ & $1.22(1.16-1.29)$ & $1.06(0.98-1.15)$ \\
\hline Parental control & $1.01(0.91-1.11)$ & $0.96(0.86-1.08)$ & $1.11(0.91-1.36)$ & $1.03(0.83-1.28)$ & $1.13(0.99-1.28)$ & $1.07(0.95-1.21)$ \\
\hline \multicolumn{7}{|l|}{ Religion } \\
\hline Protestant & 1.00 & 1.00 & 1.00 & 1.00 & 1.00 & 1.00 \\
\hline Catholic & $0.75(0.56-0.99)$ & $0.76(0.55-1.04)$ & $1.42(0.68-2.95)$ & $1.67(0.80-3.46)$ & $1.21(0.80-1.81)$ & $1.24(0.81-1.90)$ \\
\hline Muslim/Islam & $0.47(0.15-1.42)$ & $0.62(0.18-2.19)$ & 0.00 (none) $\dagger$ & 0.00 (none) $\dagger$ & $0.35(0.07-1.69)$ & $0.32(0.06-1.68)$ \\
\hline Other & $0.59(0.35-1.00)$ & $0.79(0.48-1.29)$ & $1.20(0.34-4.26)$ & $1.18(0.31-4.44)$ & $1.01(0.54-1.91)$ & $1.40(0.68-2.87)$ \\
\hline $\begin{array}{l}\text { None or } \\
\text { atheist }\end{array}$ & $0.92(0.63-1.33)$ & $0.76(0.52-1.12)$ & $2.23(0.89-5.55)$ & $1.97(0.76-5.11)$ & $1.16(0.76-1.78)$ & $1.00(0.65-1.55)$ \\
\hline
\end{tabular}

most control variables remain significant, prior (age 15) substance-use is unsurprisingly the strongest predictor of substance-use at age 18/19. There are a few significant unadjusted associations between values and future substance-use, which are broadly compatible with the crosssectional results. Thus anti-authority values consistently predict increased smoking and drug-use; traditional sexrole values, predict increases in each substance-use at age 18/19; anti-traditional politics and work ethic values again predict increased smoking. However, only two associations, that between work ethic and regular smoking and anti-authority and regular drug-use, remained (marginally) significant when adjusted for background factors and past substance-use. Associations between values and the more moderate substance-use outcomes were even weaker; in the final adjusted longitudinal model not a single association was significant.

\section{Discussion}

Returning to our three aims, we replicated the well-established cross-sectional links between values and substance-use found in the literature. Secondly, we established that background factors did not explain these cross-sectional associations. Finally, but most importantly, although some values do predict future substanceuse in simple (unadjusted) analyses, after adjusting for background and prior substance-use almost all the asso- ciations either vanish or are reduced to marginal effect sizes.

\section{Cross-sectional associations}

With respect to the cross-sectional findings, the associations between specific values and substance-use in this study are compatible with past research, but intriguingly not all values typically thought to reduce substance-use did so. This raises questions about what values are 'good' in relation to substance-use. As expected, independence and rebellious orientated (anti-authority, non-traditional or apolitical) values were associated with greater substance use. However, several unexpected associations are more notable, but require explanation. The links between traditional sex-roles and increased substance-use and between work ethic and smoking, suggests that certain cultures, competitive environments, or 'masculine' sexroles [33] encourage substance-use. Substance-use may be a coping strategy linked to the additional stress associated with work-orientated values and is compatible with research demonstrating that achievement values are linked to certain stress inducing behaviours, i.e. "taking on too many commitments" [10]. The adoption of stereotypically 'masculine' forms of coping and bonding behaviours, such as heavy-drinking or cannabis-use in response to excessive workloads, could explain this link. Equity values also predicted increased smoking rates, but only mar- 
Table 3: Longitudinal associations between values and regular substance-use behaviour at age 18/19, unadjusted and mutually adjusted odds-ratios

\begin{tabular}{|c|c|c|c|c|c|c|}
\hline \multirow[b]{2}{*}{ Predictors } & \multicolumn{2}{|c|}{ Regular smoker } & \multicolumn{2}{|c|}{ Frequent (most days) drinker } & \multicolumn{2}{|c|}{ Weekly drug-use } \\
\hline & Unadjusted & Adjusted & Unadjusted & Adjusted & Unadjusted & Adjusted \\
\hline \multicolumn{7}{|l|}{ Traditional } \\
\hline (Trad) Sex-Roles & $1.19(1.04-1.37)$ & $1.19(0.98-1.46)$ & $1.30(1.02-1.65)$ & $1.03(0.73-1.44)$ & $1.62(1.33-1.99)$ & $1.10(0.88-1.38)$ \\
\hline (Pro) Work Ethic & $1.24(1.10-1.41)$ & $1.21(1.02-1.45)$ & $1.02(0.78-1.32)$ & $0.99(0.77-1.27)$ & $1.11(0.95-1.31)$ & $1.00(0.85-1.18)$ \\
\hline (Pro) Citizenship & $1.04(0.91-1.21)$ & $1.06(0.88-1.27)$ & $0.98(0.77-1.25)$ & $0.95(0.74-1.23)$ & $1.11(0.96-1.29)$ & $1.03(0.88-1.21)$ \\
\hline \multicolumn{7}{|l|}{ Humanitarian } \\
\hline (Pro) Equity & $1.12(0.96-1.30)$ & $0.95(0.77-1.18)$ & $1.05(0.74-1.48)$ & $1.10(0.80-1.52)$ & $1.10(0.92-1.31)$ & $1.07(0.88-1.31)$ \\
\hline \multicolumn{7}{|l|}{$\underline{\text { Self-direction }}$} \\
\hline (Anti) Authority & $1.21(1.05-1.39)$ & $0.92(0.76-1.11)$ & $1.20(0.89-1.61)$ & $1.05(0.78-1.42)$ & 1.52 (1.29-1.79) & $1.33(1.10-1.61)$ \\
\hline (Anti-trad) Politics & $1.38(1.21-1.59)$ & $1.15(0.96-1.38)$ & $0.85(0.66-1.08)$ & $0.83(0.64-1.09)$ & $1.15(1.00-1.33)$ & $0.97(0.84-1.12)$ \\
\hline \multicolumn{7}{|l|}{ Self-enhancement } \\
\hline (Pro) Materialism & $1.02(0.86-1.20)$ & $1.01(0.80-1.29)$ & $1.22(0.97-1.54)$ & $1.13(0.89-1.44)$ & $1.01(0.84-1.22)$ & $0.92(0.74-1.13)$ \\
\hline (Pro) Individualism & $0.99(0.84-1.17)$ & $1.14(0.93-1.41)$ & $1.14(0.87-1.51)$ & $1.13(0.85-1.49)$ & $0.99(0.84-1.18)$ & $1.06(0.88-1.27)$ \\
\hline \multicolumn{7}{|l|}{ Prior subst-use * } \\
\hline None & 1.00 & 1.00 & 1.00 & 1.00 & 1.00 & 1.00 \\
\hline $\begin{array}{l}\text { Regular prior- } \\
\text { use }\end{array}$ & $\begin{array}{c}17.14(11.88- \\
24.71)\end{array}$ & $\begin{array}{c}16.76(11.63- \\
24.16)\end{array}$ & $3.27(1.03-10.38)$ & $2.38(0.70-8.04)$ & $7.96(5.51-11.48)$ & $5.52(3.60-8.48)$ \\
\hline \multicolumn{7}{|l|}{ Parental Smoking } \\
\hline No & 1.00 & 1.00 & 1.00 & 1.00 & 1.00 & 1.00 \\
\hline $\begin{array}{l}\text { No parent } \\
\text { figure }\end{array}$ & $3.46(1.25-9.57)$ & $1.74(0.20-14.91)$ & $\dagger$ & $\dagger$ & $1.62(0.44-5.92)$ & $0.52(0.03-7.74)$ \\
\hline Yes & $1.68(1.19-2.39)$ & $1.23(0.75-2.03)$ & $0.67(0.34-1.32)$ & $0.79(0.37-1.72)$ & $1.32(0.91-1.92)$ & $1.20(0.72-2.00)$ \\
\hline \multicolumn{7}{|l|}{ Risk taking } \\
\hline Very true & $3.38(2.29-5.01)$ & $1.37(0.80-2.33)$ & 3.39 (1.66-6.93) & $2.39(1.06-5.38)$ & $7.28(3.92-13.50)$ & $3.31(1.65-6.62)$ \\
\hline True & $2.08(1.56-2.77)$ & $1.29(0.90-1.86)$ & $1.79(1.02-3.12)$ & $1.66(0.91-3.01)$ & $3.20(2.01-5.07)$ & $2.09(1.26-3.46)$ \\
\hline $\begin{array}{l}\text { Untrue/v } \\
\text { untrue }\end{array}$ & 1.00 & 1.00 & 1.00 & 1.00 & 1.00 & 1.00 \\
\hline \multicolumn{7}{|l|}{ Sex } \\
\hline Female & 1.00 & 1.00 & 1.00 & 1.00 & 1.00 & 1.00 \\
\hline Male & $0.98(0.76-1.28)$ & $0.93(0.61-1.43)$ & $2.54(1.46-4.41)$ & $2.04(1.04-4.00)$ & $3.54(2.26-5.54)$ & $2.97(1.86-4.75)$ \\
\hline Area deprivation & $1.08(1.00-1.17)$ & $1.03(0.92-1.16)$ & $0.98(0.81-1.18)$ & $1.11(0.89-1.38)$ & $1.09(0.97-1.21)$ & $1.08(0.95-1.22)$ \\
\hline \multicolumn{7}{|l|}{ Social Class } \\
\hline Manual & 1.00 & 1.00 & 1.00 & 1.00 & 1.00 & 1.00 \\
\hline Non-manual & $0.63(0.47-0.85)$ & $0.77(0.48-1.21)$ & $2.04(1.12-3.70)$ & $2.20(1.15-4.21)$ & $0.79(0.54-1.13)$ & $0.98(0.66-1.46)$ \\
\hline
\end{tabular}


Table 3: Longitudinal associations between values and regular substance-use behaviour at age 18/19, unadjusted and mutually adjusted odds-ratios (Continued)

\begin{tabular}{|c|c|c|c|c|c|c|}
\hline \multicolumn{7}{|l|}{ Family structure } \\
\hline 2-parent & 1.00 & 1.00 & 1.00 & 1.00 & 1.00 & 1.00 \\
\hline 1-parent & $1.75(1.21-2.52)$ & $1.10(0.68-1.78)$ & $0.82(0.40-1.68)$ & $0.80(0.36-1.78)$ & $1.12(0.78-1.62)$ & $0.81(0.49-1.35)$ \\
\hline reconstituted & $2.26(1.55-3.30)$ & $1.78(1.15-2.78)$ & $0.58(0.21-1.60)$ & $0.55(0.16-1.89)$ & $1.27(0.73-2.20)$ & $1.09(0.58-2.08)$ \\
\hline other & $2.95(1.43-6.09)$ & $1.92(0.37-9.89)$ & $\dagger$ & $\dagger$ & $2.05(0.79-5.31)$ & $1.95(0.27-14.16)$ \\
\hline Low parental care & $1.16(1.06-1.26)$ & $1.05(0.92-1.19)$ & $1.15(1.02-1.29)$ & $1.11(0.97-1.28)$ & $1.17(1.07-1.27)$ & $1.04(0.92-1.16)$ \\
\hline Parental control & $1.01(0.90-1.13)$ & $0.98(0.85-1.13)$ & $0.98(0.79-1.20)$ & $0.93(0.76-1.15)$ & $1.01(0.89-1.15)$ & $0.93(0.80-1.07)$ \\
\hline \multicolumn{7}{|l|}{ Religion } \\
\hline Protestant & 1.00 & 1.00 & 1.00 & 1.00 & 1.00 & 1.00 \\
\hline Catholic & $0.88(0.65-1.20)$ & $1.03(0.72-1.48)$ & $1.07(0.63-1.79)$ & $1.10(0.64-1.87)$ & $0.73(0.52-1.03)$ & $0.67(0.46-0.97)$ \\
\hline Muslim/Islam & $0.93(0.41-2.14)$ & $1.54(0.66-3.62)$ & 0.00 (none) $\ddagger$ & 0.00 (none) $\ddagger$ & $0.52(0.15-1.74)$ & $0.51(0.14-1.86)$ \\
\hline Other & $0.64(0.35-1.20)$ & $0.92(0.41-2.08)$ & $1.01(0.33-3.03)$ & $0.80(0.26-2.49)$ & $0.68(0.33-1.39)$ & $0.67(0.29-1.57)$ \\
\hline $\begin{array}{l}\text { None or } \\
\text { Atheist }\end{array}$ & $1.05(0.65-1.71)$ & $1.24(0.67-2.30)$ & $1.68(0.90-3.12)$ & $1.51(0.83-2.74)$ & $0.77(0.49-1.21)$ & $0.61(0.39-0.97)$ \\
\hline
\end{tabular}

ginally. A surprising finding is that individualism (speculated to be associated with negative [34] outcomes) was linked to reduced substance-use; in fact, more individualistic young people had lower levels of smoking and drug use.

\section{Longitudinal associations}

Our longitudinal findings directly challenge the proposition that authoritarian or traditional values are necessarily better for health than liberal or individualist ideals [1$3]$. However, since our study only focused on substanceuse, it is possible that individualistic values predict other health and health-related outcomes such as poorer mental health. Furthermore, we did not measure values at both time points, our underlying assumption being that values are relatively stable from mid-adolescence onward (see additional file 1). This assumption has some support, but we cannot eliminate the possibility that values changed between ages 15 and 18/19. Nonetheless, this does not weaken the argument that (based on our results) moral values have poor predictive power in relation to later substance-use from mid to late-adolescence.

From a developmental perspective it is of course possible that values in childhood or early adolescence may predict uptake before age 15, but given the consensus that values are not fully formed until mid to late adolescence
[35-37] this may be a difficult (although not impossible) research question to test. A strong association between substance-use and values before age 15 may leave little variation to explain in the post-school period. However, the large increase in alcohol-use between each wave suggests there is substantial change between ages 15 and 18/ 19. Finally, compatible with the literature on values transmission (see additional file 1) we found that background factors explained very little of the cross-sectional associations between values and substance-use. This suggests that the typical structural explanations for this link (e.g. religion or class) are of minor relevance during this lifestage, although there always remains the possibility of model misspecification.

\section{Policy considerations}

Should policymakers encourage certain moral values on the assumption that this will inhibit later (early adult) substance-use? The evidence from our study suggests not, or at least not to any significant degree. If the aim is to promote values deemed socially desirable, then this is a wider moral question largely detached from public-health policy. Advocates of values education will likely focus on the cross-sectional results and the two (marginally) significant longitudinal associations between anti-authority/ political values and substance-use, while their opponents 
will likely concentrate on the small effect size(s) and the, generally, negative longitudinal findings. We do not wish to discourage innovative approaches to reducing population levels of substance-use among young people, but it is clear from our results that future values-based studies and interventions should be rigorous (i.e., a prospective study, which adjusts for relevant background factors) and focused on 'practical' significance.

\section{Conclusion}

Arguably, most people intuitively consider certain values (e.g. benevolence, equality) to be of greater ethical and social 'worth' and these values are to be encouraged. However, expanding this to encompass improved health and health-related behaviours is problematic. Our evidence suggests that these values are not necessarily 'good' (or 'bad') for you, at least in relation to substance-use.

\section{Additional material}

Additional file 1 Supplementary supporting material. Contains 2 figures; figure 1a locates specific items within the Schwartz value model; figure $1 \mathrm{~b}$ provides a simplified model of Schwartz's circumplex model. Box 1 contains a broad introduction to the Schwartz model and a summary of its 10 values and typical items used in their measurement. Table 1 shows the factor loadings of the 32 items after varimax factor analysis in relation to an 8 factor solution.

Additional file 2 Questionnaire items. List of 32 items on opinions and beliefs used in the factor analysis.

\section{Competing interests}

All authors are supported financially by the Medical Research Council of Great Britain as part of the Youth and Health Programme (WBS U.1300.00.007) and have no other competing interests.

\section{Authors' contributions}

RY wrote the majority of the manuscript, conceived the theoretical approach taken in the paper, participated in design of the final phase of the 11-16/16+ study, and performed the statistical analysis. PW conceived of the original $11-$ 16 study, and participated in its design and coordination and helped to draft the manuscript. Both authors read and approved the final manuscript.

\section{Acknowledgements}

We thank Helen Sweeting, Wolfgang Markham and Paul Aveyard for commenting on a draft manuscript. We are grateful to Prof. Shalom Schwartz for allowing us permission to reproduce the diagrams and text related to his model of values.

\section{Author Details}

MRC Social and Public Health Sciences Unit, University of Glasgow, 4 Lilybank Gardens, Glasgow G12 8RZ, UK

Received: 1 October 2009 Accepted: 26 March 2010

Published: 26 March 2010

\section{References}

1. Law S: The War for Children's Minds London: Routledge; 2006.

2. Lockwood AT: Character Education: Controversy and Consensus London: Corwin Press; 1997.

3. Lickona T: Educating for Character. How Our Schools Can Teach Respect and Responsibility New York: Bantum; 1992.

4. Lickona R: Combatting Violence with Values: The Character Education Solution. Reprint from Law Studies 1994, 19(3):1-6.

5. Haydon G: Teaching About Values: A New Approach London: Cassell; 1997
6. Bereznicki B, Brown D, Zbar V: Values Education Study Final Report. Edited by Australian Department of Education SaT. Carltion South Victoria: Mc Millan Printing Group; 2003.

7. Kluckhohn C: Values and value-orientation in the theory of action: An exploration in definition and classification Cambridge, MA: Havard University Press; 1951.

8. Davidov E, Schmidt P, Schwartz SH: Bringing values back in - The adequacy of the European Social Survey to measure values in 20 countries. Public Opin Q 2008, 72(3):420-445.

9. Schwartz $\mathrm{SH}$ : Universals in the content and structure of values: theoretical advances and empirical tests in 20 countries. In Advances in Experimental Social Psychology Volume 25. Edited by: Zanna M. New York: Academic Press; 1992:1-65.

10. Bardi A, Schwartz SH: Values and behavior: Strength and structure of relations. Pers Soc Psychol Bull 2003, 29(10):1207-1220.

11. Schwartz SH, Bardi A: Value hierarchies across cultures - Taking a similarities perspective. J Cross Cult Psychol 2001, 32(3):268-290.

12. Liu H, Yu S, Cottrell L, Lunn S, Deveaux L, Brathwaite NV, Marshall S, Li X, Stanton $B$ : Personal values and involvement in problem behaviors among Bahamian early adolescents: a cross-sectional study. $B M C$ Public Health 2007, 7:135.

13. Cole M, Stanton B, Deveaux L, Harris C, Lunn S, Cottrell L, Clemens R, Li XM, Marshall S, Baine RM: Latent class analysis of risk behaviors among Bahamian young adolescents: Relationship between values prioritization and latent class. Soc Behav Pers 2007, 35(8):1061-1076.

14. Rees KS, Thompson S, Rees C, Cluphf D: Unexpected Findings in an Alternative High School: New Implications for Values Education. Californian J Health Promot 2005, 3(1):130-139.

15. Garnier HE, Stein JA: Values and the family - Risk and protective factors for adolescent problem behaviors. Youth Soc 1998, 30(1):89-120.

16. Garnier HE, Stein JA: An 18-Year Model of Family and Peer Effects on Adolescent Drug Use and Delinquency. J Youth Adolesc 2002, 31(1):45-56.

17. Goff BG, Goddard HW: Terminal core values associated with adolescent problem behaviors. Adolescence 1999, 34(133):47-60.

18. Dollinger SJ, Kobayashi R: Value correlates of collegiate alcohol abuse. Psychol Rep 2003, 93(3):848-850.

19. Kristiansen CM: Smoking, health behavior, and value priorities. Addict Behav 1985, 10(1):41-44.

20. Kristiansen CM: Smoking, health behavior, and values: a replication, refinement, and extension. Addict Behav 1985, 10(3):325-328.

21. Chen X, Tang X, Li X, Stanton B, Li H: Core Human Values and Their Interactions with Pro-Tobacco Factors on Cigarette Smoking: The Role of Factors not Explicitly Related to a Risk Behavior. Californian J Health Promot 2008, 6(1):23-39.

22. West $P$, Sweeting $H$ : Background, Rationale and Design of the West of Scotland 11 to 16 study. Glasgow, MRC Social \& Public Health Sciences Unit Working Paper No. 531996.

23. Ecob R, West $P$, Sweeting $H$ : The West of Scotland 11 to 16 Study: schools, sample design and implementation issues. Glasgow, MRC Medical Sociology Unit Working Paper No. 611996.

24. Sweeting $H$, Der $G$, West $P$ : Bias, attrition and weighting in respect of the West of Scotland 11 to 16 Study's baseline, S2 and S4 surveys. Glasgow, MRC Social \& Public Health Sciences Unit Working Paper No. 92001.

25. Helve H: Reflexivity and changes in attitudes and value structures. In Youth, citizenship and empowerment Edited by: Helve H, Wallace C. Chippenham, Wiltshire: Ashgate; 2001:201-218.

26. Bynner JM, Romney DM, Emler NP: Dimensions of political and related facets of identity in late adolescence. J Youth Stud 2003, 6:319-335.

27. Bynner J: "Coping with Transition: ESRC's new 16-19' Initiative.". Youth and Policy 1987, 22:25-28.

28. Macintyre S, Annandale E, Ecob R, Ford G, Hunt K, Jamieson B, Maclver S, West P, Wykes S: The West of Scotland Twenty-07 Study: Health in the Community. In Readings for a new public health Edited by: Martin C, MacQueen DJ. Edinburgh: Edinburgh University Press; 1989:56-74.

29. McLoone P: Carstairs scores for Scottish postcode sectors from the 2001 Census Glasgow: MRC Social and Public Health Sciences Unit; 2004.

30. ONS: Standard Occupational Classification Volume 2. London: The Stationery Office; 2000.

31. Klimidis S, Minas $I H$, Ata AW: The PBI-BC: A brief current form of the Parental Bonding Instrument for adolescent research. Comprehensive Psychiatry 1992, 33(6):374-377. 
32. Fuller M: Drug use, smoking and drinking among young people in England in 2005. London: National Statistics; 2006.

33. Gough B: Try to be healthy, but don't forgo your masculinity: deconstructing men's health discourse in the media. Soc Sci Med 2006, 63(9):2476-2488.

34. Layard R, Dunn J: A good childhood: Searching for values in a competitive Age London: Penguin Books Ltd; 2009.

35. Hofstede G, Hofstede GJ: Cultures and Organizations, Software of the Mind: Intercultural Cooperation and its Importance for Survival New York: McGrawHill; 2005

36. Inglehart R: Culture shift in advanced industrial society Princeton, N.J.: Princeton University Press; 1990.

37. Inglehart R: Modernization and postmodernization: Cultural, economic, and political change in 43 societies Princeton, N.J.: Princeton University Press: 1997

\section{Pre-publication history}

The pre-publication history for this paper can be accessed here: http://www.biomedcentral.com/1471-2458/10/165/prepub

doi: 10.1186/1471-2458-10-165

Cite this article as: Young and West, Do 'good values' lead to 'good' healthbehaviours? Longitudinal associations between young people's values and later substance-use BMC Public Health 2010, 10:165

Submit your next manuscript to BioMed Central and take full advantage of:

- Convenient online submission

- Thorough peer review

- No space constraints or color figure charges

- Immediate publication on acceptance

- Inclusion in PubMed, CAS, Scopus and Google Scholar

- Research which is freely available for redistribution

Submit your manuscript at www.biomedcentral.com/submit
C) Biomed Central 